\title{
O Jogo das Trevas: Heidegger, Schelling e Espinosa
}

[The Game of Darkness: Heidegger, Schelling and Spinoza]

\section{Vittorio Morfind}

Resumo: Este artigo visa analisar, em primeiro lugar, a problemática do panteísmo relativa ao determinismo e à liberdade, tratada por Schelling quando este se posiciona sobre o "erro de Espinosa". Em segundo lugar, procuraremos entender, tanto no pensamento schellinguiano quanto na sua interpretação heideggeriana, a afirmação de Heidegger de que haveria em Schelling um "tratado que abala a Lógica de Hegel, antes mesmo dela aparecer". Em terceiro lugar, seguindo o percurso da linhagem Descartes-Kant-Hegel na história da metafísica, procuraremos elaborar a trajetória do problema da "liberdade e do caráter inteligível", confrontando-a com a solução schellinguiana, a fim de analisa-la mediante o conflito da origem do mal e a impossibilidade da liberdade. Finalmente, procuraremos responder à acusação de "erro de Espinosa" e com isso propor a abertura para interpretações ulteriores de Espinosa, principalmente no que diz respeito ao problema de liberdade humana.

Palavras-chave: Schelling, Heidegger, Kant, Espinosa, Liberdade, o Mal.

Abstract: This article aims to analyze, first, the problem of pantheism concerning determinism and freedom, treated by Schelling when he defines a position concerning "Spinoza's error". Secondly, we will seek to understand, both in Schellingian thought and in his Heideggerian interpretation, Heidegger's statement that there would be in Schelling a "treatise that shakes Hegel's Logic even before it appears". Thirdly, following the path of the Descartes-Kant-Hegel lineage in the history of metaphysics, we will seek to elaborate the trajectory of the problem of "freedom and intelligible character", confronting the former one with the Schellingian solution, in order to analyze it through the conflict of the origin of evil and the impossibility of freedom. Finally, we will endeavor to respond to the accusation concerning "Spinoza's error" and thereby propose the opening for further interpretations of Spinoza, especially with regard to the problem of human freedom.

Keywords: Schelling, Heidegger, Kant, Spinoza, Freedom, Evilness.

\footnotetext{
${ }^{*} \mathrm{O}$ presente artigo é uma versão para o público brasileiro de um texto originalmente publicado como capítulo do livro Il tempo della moltitudine. Materialismo e politica prima e dopo Spinoza, Roma: Manifestolibri, 2005, pp.149172. A tradução do italiano foi realizada por Daniel Santos Silva [notação de tradutor identificada como "Nota DSS"], a tradução das citações e filósofos alemães foram feitas por Fabio Nolasco [notação de tradutor identificada como "Nota FN"], revisão geral feita por Ericka Marie Itokazu.

${ }^{*}$ Professor da Università degli Studi di Milano-Bicocca. Doutor em Ciência Política pela Université de Paris VIII (Vincennes - Saint-Denis). E-mail: vittorio.morfino@unimib.it. ORCID: https://orcid.org/0000-0003-4512-9759.
} 
(...) uma paixão é para nós como um caráter temporário e diferente, que substitui o outro e elimina os signos, até então invariáveis, pelos quais ele se exprimia. (Marcel Proust, Du côté de chez Swann)

\section{Schelling na história da metafí- sica}

Em 1936, quando Heidegger introduz aos estudantes a obra de Schelling nas lições dedicadas às Investigações filosóficas sobre a essência da liberdade humana, ele apresenta-a nestes termos: “(...) é o que de maior fez Schelling e, ao mesmo tempo, uma das obras mais profundas da filosofia alemã e, portanto, da filosofia ocidental' '1 . Não seria este, pois, um tratado que tem em mira uma questão particular, como havia pensado Hegel, mas sim uma obra filosófica fundamental dedicada não à questão do livre-arbítrio do homem, mas à liberdade do Ser "ao qual o homem tem de ser reconduzido para que se torne verdadeiramente homem"2]. Entretanto, em vez de restituir o conjunto da interpretação heideggeriana de Schelling como cume e naufrágio do idealismo alemão ou, ainda, apenas colher dela seu sentido no quadro da história da metafísica, tentarei interrogar o texto nas suas margens, lá onde Heidegger desenha relações de oposição ou de continuidade com algumas figuras fundamentais do pensamento moderno: Espinosa, Kant, Hegel. E, talvez, é desses acenos marginais que será possível aceder à compreensão daquilo que está em jogo na interpretação heideggeriana de Schelling.

1) Espinosa. A proximidade de Schelling com respeito à filosofia espinosana foi sublinhada por ele mesmo (na célebre carta a Hegel de 1795 em que declara "ich bin indessen Spinozist geworden!" ${ }^{3}$,, por escritos polêmicos (primeiro entre todos, como não, o de Jacobi) e por uma ininterrupta série de artigos e ensaios ao longo de todo o Novecentos. A afirmação de Hei-

\footnotetext{
${ }^{1}$ HEIDEGGER, M. Schellings Abhandlung über das Wesen der menschlichen Freiheit (1809), hrsg. von H. Feick, Tübingen: Max Niemeyer Verlag, 1971, p.2. [* As traduções de Heidegger foram feitas a partir do italiano por Daniel Santos, e revisadas em cotejo com o alemão por Fabio Mascarenhas Nolasco, a não ser quando especialmente indicado. Nota FN]

2 Ibidem, p. 11. Acrescenta Heidegger: "Note-se: não a liberdade como propriedade (Eigenschaft) do homem, e sim o homem como propriedade (Eigentum) da liberdade" (Ibidem).

${ }^{3}$ Carta de Schelling a Hegel, em 4 de fevereiro de 1795, em Briefe von und an Hegel, Bd. I, hrsg. von J. HOFFMEISTER, Hambruf, Meiner, 1952, p. 22.
} 
degger tem então a força de um tiro de canhão para o senso comum filosófico:

O fato que a filosofia de Schelling tenha sido tomada por espinosismo recai naquela história curiosa de malentendidos que todos os filósofos sofrem da parte de seus contemporâneos. Se há um sistema que Schelling combateu de modo radical [von Grund aus bekämpfte], é propriamente aquele de Espinosa. E se houve um pensador que reconheceu o verdadeiro erro de Espinosa, este é Schelling. ${ }^{4}$

Duas indicações fundamentais: 1) não somente Schelling não é espinosista, mas pelo contrário, se se quer ler Schelling de modo correto, deve-se colher na sua filosofia esta oposição radical ao sistema espinosano que, por assim dizer, o atravessa; 2) no sistema espinosano existe, segundo Heidegger, um erro fundamental que Schelling especificou da melhor forma.
2) Kant. A relação KantSchelling vem caracterizada por Heidegger em termos de continuidade/aprofundamento. Se idealismo em sentido amplo significa "interpretação da essência do Ser como 'ideia', como ser-representado pelo ente em geral' 5 , para entender a linha da metafísica moderna DescartesLeibniz, somente com Kant o eu representativo ele atinge sua essência, a liberdade, abrindo caminho ao idealismo entendido em sentido histórico6.

Kant, sobre a via que o leva da Crítica da razão pura à Crítica da razão prática, reconhece todavia que a essência autêntica do eu não é o eu penso, mas o eu ajo; dou-me a mim mesmo a lei trazendo-a do fundamento da essência, eu sou livre. Nesse ser-livre, o eu está verdadeiramente consigo, não distante de si, mas verdadeiramente $\mathrm{em}$ si. $\mathrm{O}$ eu como eu represento, a ideia, vem então con-

\footnotetext{
${ }^{4}$ HEIDEGGER, M. Schellings Abhandlung über das Wesen der menschlichen Freiheit (1809), FEICK, H. (org.), Tübingen: Max Niemeyer Verlag, 1971; tr. it. MAZZARELLA, E. e TATASCIORE, C. (orgs.), Nápoles: Guida, 1998, p. 41 .

5 Ibidem, p. 110.

6 "O idealismo como sistema foi fundado pela Doutrina da Ciência de Fichte, completado de maneira essencial pela filosofia da natureza de Schelling, elevado a um nível superior pelo seu Sistema do idealismo transcendental, consumado por seu Sistema da identidade e fundado propriamente num movimento conclusivo apenas pela Fenomenologia do espírito, de Hegel”, ibidem, p.109.
} 
cebido a partir da liberdade. O idealismo como interpretação do Ser entende então o ser-em-si do ente como ser-livre; o idealismo é dentro de si idealismo da liberdade.7

Enquanto partícipe do idealismo, Schelling é, segundo Heidegger, profundamente devedor de Kant pelo conceito de liberdade como "subsistência própria e autodeterminação na própria lei essencial" (Eigenständigkeit und Selbstbestimmung im eigenen Wesengeset $2^{8}$, ao exceder esse movimento de pensamento, ele aprofunda o conceito de Kant mudando sua filosofia de terreno: "o idealismo alcançou de fato o conceito formal da liberdade (...) mas ainda não compreendeu o fato [Tatsache] da liberdade humana na sua facticidade [Tatsächlichkeit]'"9?.

3) Hegel. A perspectiva a partir da qual o senso comum filosófico considera a relação HegelSchelling foi imposta pelo célebre movimento teórico do Prefácio da Fenomenologia do espírito: o absoluto de Schelling é "a noite em que 'todos os gatos são pardos', como se costuma dizer" 10 , Quer se re- fira ao amigo de um tempo ou a seus maus divulgadores, como lhe assegura em uma carta, certo é que esse juízo tem a força de uma sentença de condenação que transforma a filosofia schellinguiana em um momento do processo histórico-filosófico que deveria conduzir ao idealismo absoluto de Hegel. Que Schelling continue a viver e a escrever após o florir daquele botão tardio de Suábia é uma pura contingência sem significado algum do ponto de vista da weltgeschichtlich. Heidegger distancia-se precisamente de uma perspectiva de tal gênero. O simples movimento de dedicar um curso à única obra publicada por Schelling em vida, depois do surgimento da Fenomenologia (se são excluídas obras de caráter polêmico), é suficiente para mostrar que existe um pensamento de Schelling para além de Hegel, ou seja, para além da filosofia schellinguiana como posição subordinada àquela do saber absoluto. Longe porém de limitar-se a uma valorização somente implícita do pensamento de Schelling, Heidegger afirma explicitamente a força desse pensamento próprio em relação àquele de Hegel:

\footnotetext{
7 Ibidem, p. 111.

${ }^{8}$ Ibidem, p. 109.

${ }^{9}$ Ibidem.

10 HEGEL, G.W.F. Phänomenologie des Geistes, in GW, Bd. 9, hrsg. von W. Bonsiepen - R. Heede, Hamburg: Meiner, 1980, p. 17 [Nota FN: trad. em português de Paulo Meneses, Parte I, Petrópolis, Vozes, 1992, p. 29].
} 
Quando se cita o tratado schellinguiano sobre a liberdade apenas ocasionalmente, a fim de assim documentar uma certa visada de Schelling sobre o mal e a liberdade, não se tem desse tratado conceito algum. Torna-se agora também visível em que medida a avaliação de $\mathrm{He}$ gel sobre esse tratado, embora reconhecedora, é falha: trata-se apenas de uma questão particular! O tratado que abala [erschüttert] a Lógica de Hegel antes mesmo dela aparecer! $[11$

Não apenas, pois o pensamento de Schelling não desvanece em frente ao surgir do pensamento hegeliano, mas põe em questão ante-litteram os fundamentos de seu sistema (erschüttern significa abalar, fazer tremer, mas também romper), a grande lógica, lá onde os pensamentos de Deus são recolhidos antes de tornar-se mundo.

Antes de aproximarmo-nos do conteúdo verdadeiro e próprio do tratado, reassumamos breve- mente as coordenadas através das quais Heidegger nos permite situar o pensamento de Schelling na história da metafísica moderna: Schelling refuta Espinosa, aprofunda Kant, faz vacilar Hegel. Retomaremos analiticamente esses pontos, contudo em ordem inversa.

\section{O tratado sobre a liberdade}

As Investigações ${ }^{12}$ schellinguianas partem da polêmica com algumas das célebres teses de Jacobi presentes em Sobre a doutrina de Espinosa em cartas ao Senhor Moses Mendelssohn nas quais se conectavam de modo estreito racionalismo, panteísmo e fatalismo (bem resumida na célebre frase de Lessing: "não há outra filosofia senão a de Espinosa" 13 . Numa detalhada análise dos diferentes sentidos que se pode atribuir ao conceito de panteísmo, Schelling dedica a primeira parte de sua obra para mostrar como, em realidade, do panteísmo não segue necessariamente a negação da liberdade. Ao contrário, se o compreendemos corretamente, o panteísmo implica liberdade:

\footnotetext{
${ }^{11}$ HEIDEGGER, M. Schellings Abhandlung, op. cit. p. 117.

12 SCHELLING, F. W. J. Philosophische Untersuchungen über das Wesen der menschlichen Freiheit und die dammit zusammenhängenden Gegenstände, in SW, Bd. 4, pp. 238-239.

13 JACOBI, F.H. Über die Lehre des Spinoza, hrsg. von Hammacher et alii, Hamburg: Meiner, 2000, p. 23.
} 
Se já não fosse vivente [por si] aquilo que é compreendido em outro, então haveria uma compreensibilidade sem compreendido, i.e., nada seria compreendido. Um ponto de vista muito mais alto é assegurado pela consideração da própria essência divina, cuja ideia contradiria completamente uma sequência que não é produção, i.e., o pôr de um autossubsistente. Deus não é um Deus dos mortos, mas dos viventes. É incompreensível como a essência completamente perfeita se aprazeria mesmo que em face da mais completa das máquinas. Como quer que se queira pensar o tipo de sequência das essências a partir de Deus, ela nunca pode ser uma sequência mecânica, de modo algum um mero efetuar ou colocar em que o efetuado não é nada por si próprio; tampouco uma emanação em que o que emana permaneça o mesmo que aquele do qual emanou, portanto nada próprio, autosubsistente. A sequência das coisas a partir de Deus é uma automanifestação de Deus. Deus, contudo, pode se manifestar a si apenas naquilo que lhe é semelhante, em essências livres que agem a partir de si próprias; para cujo ser não há nenhum outro fundamento senão Deus, as quais, porém, são tal como Deus é. Ele fala e aí estão elas. Mesmo se fossem todos os seres criados apenas pensamentos do íntimo divino, já por isso haveriam de ser vi$\operatorname{vos} 14$

Assim, o panteísmo não implica, de maneira alguma, conclusões espinosistas, como considerava Jacobi, mas pelo contrário, segundo Schelling, só internamente ao panteísmo é possível pensar a liberdade: "imanência em Deus e liberdade contradizem-se tão pouco que unicamente o livre, e na medida em que é livre, é em Deus; o não-livre, e na medida em que não é livre, [é] necessariamente fora de Deus" 15 .

\footnotetext{
14 SCHELLING, F.W.J. Philosophische Untersuchungen über das Wesen der menschlichen Freiheit und die damit zusammenhängenden Gegenstäande, in: Sämtliche Werke (SW), vol 4, pp 238-239. [Nota FN: as traduções para o português a seguir foram feitas diretamente do alemão por Fábio Nolasco]

15 Ibidem, p. 239.
} 
Uma vez estabelecido que liberdade e sistema podem conviver, Schelling enfrenta a questão fundamental, qual seja: o problema da liberdade de que o idealismo teria fornecido apenas um conceito formal (forma no sentido daquilo que determina a essência, anota Heidegger), mas não vivente, que residiria em uma "faculdade do bem e do mal" (Vermögen des Guten und des Bösen $)^{16}$. Aqui, contudo, um novo problema para o panteísmo, já que "ou se concede um mal efetivo, e assim é inevitável implicar o mal na substância infinita ou na própria vontade originária, e com isso o conceito de uma essência sumamente perfeita é completamente destruído; ou é preciso que de alguma maneira a realidade do mal seja negada, com o que, no entanto, o conceito real da liberdade ao mesmo tempo desaparece" 17 . Perde-se, pois, ou Deus ou a liberdade - ao menos se não nos abandonamos à teoria dos dois princípios (que Schelling chama, no tratado, de dualismo) e, neste caso perde-se entretanto a razão ("o dualismo ... é apenas um sistema do autodilaceramento e desespero da razão, 18 . A solução schellinguiana, pela qual procura salvar Deus, a razão e a liberdade no seu panteísmo, encontra-se em uma distinção que ele pôs na filosofia da natureza: "a filosofia da natureza do nosso tempo estabeleceu na ciência, em primeiro lugar, a diferenciação entre a essência, enquanto existe, e a essência, enquanto é mero fundamento [blos Grund] de existência"19. Por essa distinção entre existência e fundamento, Schelling chegará a explicar o mal.

Deus deve ter em si mesmo o fundamento de sua existência, e esse fundamento, se se quer tornálo humanamente compreensível, deve ser pensado como o desejo que o eterno experimenta ao gerar a si próprio, um querer no qual não há intelecto, mas um querer do intelecto (genitivo objetivo), presságio do intelecto. Esse desejo foi desde muito tempo suplantado pelo ser mais alto, surgido dele, e todavia, embora não perceptível, é concebível pelo pensamento:

Segundo o ato eterno da automanifestação, no mundo tal como o visamos agora, tudo é regra, ordem e forma; mas no fundo subjaz sempre

\footnotetext{
16 Ibidem, p. 244.

17 Ibidem, p. 245.

18 Ibidem, p. 246.

${ }^{19}$ Ibidem, p. 249.
} 
ainda o sem-regra [Regellose], como se ele pudesse irromper mais uma vez, e em lugar nenhum parece que a ordenação e a forma seriam o originário, mas que um semregra inicial teria sido ordenado. Isso é nas coisas a base inapreensível da realidade, o resto que nunca se esvai, aquilo que não se deixa dissolver no entendimento mesmo com o maior esforço, mas que permanece eternamente no fundo [im Grunde]. Dessa ausência de entendimento nasceu, em sentido estrito, o entendimento. Sem essa escuridão antecedente não há qualquer realidade da criatura; a treva é seu necessário legado. 20

A partir, pois, da distinção entre fundamento e existência em Deus, Schelling desencadeia o processo através do qual Deus mesmo se gera, gerando a natureza e a história. Frente a essa verdadeira teo/cosmo-gonia, combateu-se entre uma atitude de admiração à criativiadade filosófica de Schelling e à ironia de Schopenhauer que diante de um "relatório detalhado sobre um Deus do qual o senhor autor dá a entender possuir conhecimento íntimo, posto que nos descreve até mesmo o seu surgimento", deplora o fato de que "ele não gaste uma só palavra para mencionar como teria então alcançado tal conhecimento'"21. Em tal contexto, talvez seja mais interessante tomá-la como pura estratégia, verdadeira e própria luta filosófica para salvar a razão, Deus e liberdade 22 .

Ora, em cada ser da natureza, em cada graduação sua, estão presentes os dois princípios, mas apenas no homem de forma plena: "no ser humano está o poder inteiro do princípio tenebroso e também nele, simultaneamente, toda a força da luz. Nele está o mais profundo abismo e o mais alto céu (der tiefste Abgrund und der höcheste Himmel), ou ambos os centros" 23. O mal então não pode ser compreendido como malum metaphysicum, como limitação (ou seja, como privação), mas como positiva perversão dos dois princípios:

\footnotetext{
${ }^{20}$ Ibidem, p. 251-252.

21 SCHOPENHAUER, A. Preisschrift über die Freiheit des Willens, in Werke (W), vol 4, p. 84.

22 "Quiçá derradeiramente, e pos isso com extrema fúria, Schelling luta para ganhar a batalha da razão." (G. ALBIAC, La sinagoga vacía, Madrid, Ediciones Hiperión, 1987, p. 337.)

23 SCHELLING, F.W.J. Philosophische Untersuchungen cit., p. 255.
} 
Pois já a simples ponderação de que o ser humano, a mais perfeita de todas as criaturas visíveis, é a única capaz do mal, mostra que o fundamento disso não poderia de maneira alguma dever-se à falta ou privação. O diabo, segundo a visada cristã, não era a mais limitada das criaturas, senão que muito mais a mais ilimitada. A imperfeição no sentido metafísico geral não é o caráter usual do mal, posto que ele frequentemente se mostra unificado a uma excelência das forças singulares, as quais com muito menor frequência acompanham o bem. 24

Schelling explica pois o mal pelo fundamento, o qual não está fora de Deus, mas é em Deus mesmo. Mas o mal não é o fundamento, já que, contrariamente, "a vontade do fundamento já na primeira criação coexcita a vontade própria da criatura, a fim de que, quando surgir o espírito como a vontade de amor, este encontre algo que lhe resista, no qual possa se efetivar" 25 (e isso possa ser apreendido, segundo Schelling, no irracional e no acaso, que se encontra conectado com o necessário, especialmente nos seres orgânicos, signo de uma "individualidade ativa" ${ }^{26}$, operando neles). Sobretudo, no fazer da individualidade mesma, o mal consiste no perverter a relação entre os dois princípios, em vez de base e órgão da espiritualidade, um princípio "dominante e vontade-total (...), e em contrapartida, do espiritual em si um meio (...)"27, Uma perversão desse gênero é possível somente no homem, ou seja, no reino do espírito, da história, enquanto no animal o vínculo entre os dois princípios é determinado e não passível de perversão (o animal não é, assim, capaz de mal, o ser capaz do mal é propriamente aquilo que constitui a essência do homem).

Trata-se de compreender, nesse quadro, em que sentido a liberdade consiste em uma faculdade do bem e do mal. Schelling re-

\footnotetext{
24 Ibidem, p. 260-261.

25 Ibidem, p. 267-268. A propósito, escreve Parayson: “A impossibilidade de separar a liberdade humana da liberdade divina implica que o mal, posto que é o resultado da liberdade humana, e dela apenas, tem uma prehistória sobrehumana, um fundo metafísico, um pressuposto [antefatto] escuro e abissal. Isso tem a sua origem remota no fundamento obscuro da essência divina, que o próprio Deus supera e vence no evento portentoso do seu devir, e a sua causa próxima e imediata na liberdade humana." (Introduzione a F.W.J. Schelling, Scritti sulla filosofia della religione, la libertà, op. cit., p. 15).

26 Ibidem, p. 268.

27 Ibidem, p. 281.
} 
cusa de modo preciso tanto a concepção da liberdade como liberum arbitrium indifferentiae quanto a concepção determinista ou, como ele a chama, pré-determinista: "em ambas é igualmente desconhecida aquela necessidade superior, (...) necessidade que brota da essência do próprio agente" 28 , A liberdade se identifica, pois, com essa mais alta necessidade, que coincide com a ação que segue da própria essência. O problema se desloca então para a liberdade da essência. E eis a resposta schellinguiana: “o ser humano é na criação originária (...) uma essência indecisa, (...) mas ele próprio pode decidir-se. No entanto, essa decisão não pode ocorrer no tempo"29. O homem é, pois, livre para escolher o bem e o mal não no tempo, mas na eternidade, antes que o tempo seja; escolhe sua essência no eterno e dessa escolha seguem necessariamente todas as suas ações no tempo: o agir do homem, por assim dizer, não se torna, mas é por natureza eterno.

Para retomar o principal do tratado, eis os dois movimentos teóricos fundamentais:

- a liberdade como autodeterminação intemporal da sua pró- pria essência;

- o mal como perversão da relação entre os dois princípios cooriginários em Deus.

Estamos agora em condições para retornar ao texto de Heidegger e procurar compreender melhor o sentido dessa relação de continuidade e de oposição que ele estabeleceu com Espinosa, Kant, Hegel.

\section{O princípio das trevas e a trans- parência do conceito}

Assinalamos para o fato de que Heidegger põe em discussão a reconstrução hegeliana da história do idealismo na qual Schelling não seria senão um momento necessário (a reequilibrar o subjetivismo fichteano) mas parcial e subordinado ao idealismo absoluto. Em realidade, Schelling, longe de ser um momento do desenvolvimento em direção ao saber absoluto, é o pensador que "empurra o idealismo alemão desde o seu interior para fora e além de sua própria posição fundamental' 30 . Aqui, o que está em jogo é a relação com Hegel, como mostra esta exclamação de Heidegger: "o tra-

\footnotetext{
28 Ibidem, p. 275.

${ }^{29}$ Ibidem, p. 277

${ }^{30}$ HEIDEGGER, M. Schellings Abhandlung, op.cit., p. 4.
} 
tado que abala a Lógica de Hegel antes mesmo dela aparecer!"

Em que sentido o tratado de Schelling abala a Lógica? A lógica de Hegel é a completude da metafísica moderna, daquele movimento filosófico posto em ato pela primeira vez por Descartes, para quem a medida do ser está no pensamento, no sujeito. A lógica é a ciência da ideia não mais entendida como o conteúdo mental cartesiano, mas como coração mesmo da totalidade, como aquele processo de pensamento que no seu fazer-se institui ao mesmo tempo as estruturas fundamentais do ser da natureza e da história. Costuma-se citar a descarada imagem hegeliana segundo a qual a lógica seria "a apresentação (Darstellung) de Deus, tal como ele é em sua essência eterna antes da criação da natureza e de um espírito finito" 31. Aqui é possível compreender, naturalmente, sob a condição de renunciar a toda transcendência de Deus e a toda anterioridade entendida em sentido temporal. Não se pode, de fato, separar a ideia do processo pelo qual ela continuamente põe diante de si uma alteridade (o outro do pensamento, do conceito, ou seja, o acidental, o contingente, o acaso) e continuamente a supera dando-lhe forma:

A identidade da ideia consigo mesma - escreve Hegel - é um com o processo; o pensamento que liberta a efetividade da aparência [Schein] da alterabilidade sem finalidade e a transfigura [verklärt] em ideia, não tem de representar essa verdade da efetividade como o repouso morto, como uma mera imagem, fraca, sem impulso e movimento, como um gênio ou um número ou um pensamento abstrato; a ideia, em virtude da liberdade que o conceito alcança nela, tem também a oposição mais dura dentro de si; seu repouso consiste na segurança e na certeza com as quais ela eternamente a gera e eternamente a supera e, nela, junta-se consigo mesma. ${ }^{32}$

Em que sentido, então, o Schelling do tratado abala a lógica de Hegel? Enquanto, em Hegel, Deus é o lu-

\footnotetext{
${ }^{31}$ HEGEL, G.W.F. Wissenschaft der Logik, in GW, Bd. 11, hrsg. Von F. Hogemann - W. Jaescke, p. 21. [Nota FN: tradução portuguesa a cargo de Ch. Iber, F. Orsini, M. Miranda, vol. 1, Petrópolis-Bragança Paulista, Vozes, 2016, p. 52]

32 Ibidem, Bd. 12, p. 177, tr. Br. citada, p. 242 (grifos do autor)
} 
gar das puras estruturas lógicas do ser que encontram a opacidade da contingência e da acidentalidade no fazer-se mundo, mas somente no caminho para a transparência do espírito (isto é, de um Deus que enfim se sabe como tal), em Schelling, a luz do pensamento é em Deus precedida, em um sentido intemporal, por um princípio tenebroso que a deseja e ao mesmo tempo a individualiza, e assim não é de modo algum a ela redutível. Trata-se daquele conceito que Heidegger denomina de Seynsfuge, encaixe do ser, articulação do ser. Como escreve Eugenio Mazzarela,

o fundamental do tratado schellinguiano de 1809 consiste em ter levado a problemática da dialética especulativa do idealismo sobre um terreno, a liberdade, de onde 'salta' a solução integralmente lógica do nexo ontológico, a reinvindicação de que no 'conceito' o ser e o pensar se convertem integralmente e que a participação nessa compreensão recíproca integral [seja] completamente atualizável, no sentido de uma sua translucidez sem resíduo, para o pensamento humano sub specie do trabalho filosófico do espírito. ${ }^{33}$

Em substância, Schelling faria vacilar a concepção hegeliana da liberdade como processo histórico de autoapropriação da totalidade - liberdade que, nessa ótica, não pode senão ser coletiva, inserida nas instituições políticas.

Em Schelling, a impossível transparência imposta pela Seynsfuge mostra o limite do conceito idealista de liberdade como autodeterminação a partir de uma essência própria: a liberdade vivente necessita de uma definição mais profunda, a liberdade vivente é faculdade do bem e do mal. Schelling faria assim vacilar o inteiro sistema hegeliano pensando a liberdade como potencialidade de transgressão contra Deus: o mal não se cura sem cicatrizes, como na Fenomenologia hegeliana ${ }^{34}$, mas é o sintoma da existência do conflito no ser di-

\footnotetext{
${ }^{33}$ MAZZABELLA, E. Presentazione a M. Heidegger, Schelling, op.cit., p. 31.

34 "As feridas do espírito curam sem deixar cicatrizes. O fato não é o imperecível, mas é reabsorvido pelo espírito dentro de si; o que desvanece imediatamente é o lado da singularidade presente no fato - seja como intenção, seja como negatividade e limitação aí-essente do fato." (HEGEL, G.W.F. Phänomenologie des Geistes, op.cit., p. 360) [Nota FN: trad. brasileira, op.cit., p. 444]

35 Sobre o mal físico e o mal moral cf. MOISO, F. Vita natura libertà. Schelling (1795-1809), Milão: Mursia, 1990, pp. 294-335.
} 
vino mesmo 35

\section{A liberdade e o caráter inteligí- vel}

No percurso da metafísica moderna que conduz de Descartes a Schelling, sem dúvida, em Kant está o nó fundamental: é Kant, de fato, que - segundo Heidegger formula o conceito formal de liberdade como "autossubsistência como subsistência própria na própria lei essencial" 36, Há um evidente débito no tratado sobre a liberdade nos confrontos de Kant que todavia Schelling não sublinha de modo suficientemente claro e que mesmo Heidegger, em comentários, não contribui para iluminar. Escreve Schelling:

O ser humano é na criação originária (...) uma essência indecisa, (...) mas ele próprio pode decidirse. No entanto, essa decisão não pode ocorrer no tempo; ela ocorre fora de todo tempo e, portanto, coincide com a primeira criação (embora enquanto um ato diverso dela). $\mathrm{O}$ ser humano, embora nasça no tempo, foi, no entanto, criado no começo da criação (o centro).

$\mathrm{O}$ ato mediante o qual sua vida é determinada no tempo não pertence ele mesmo ao tempo, mas à eternidade: ele não antecede à vida também segundo o tempo, mas decorre através do tempo (inapreendido por ele) como um ato eterno segundo a natureza. Mediante esse ato a vida do ser humano alcança até ao começo da criação; por isso ele, mediante tal ato e mesmo fora do criado, é livre e ele próprio começo eterno. Embora essa ideia possa ao modo comum de pensar parecer tão incompreensível, em cada ser humano, porém, há um sentimento concordante com isso [Schelling se refere ao sentimento de responsabilidade que sentimos pelas nossas ações; V.M.], como se ele já tivesse sido o que é desde toda eternidade, e de modo algum apenas veio a ser no tempo. Por isso, a despeito da inegável necessidade de todas as ações, e mesmo que

${ }^{36}$ HEIDEGGER, M. Schellings Abhandlung, op.cit., p. 109. 
cada um, quando atenta a si próprio, tenha de conceder que de modo algum é bom ou mau por acaso ou arbitrariamente, o mal, p.ex., aparece a si como nada menos que coagido (posto que a coação pode apenas ser sentida no devir, não no ser), mas faz suas ações com vontade, não contra sua vontade. Que Judas tenha se tornado um traidor de Cristo, não o podia alterar ele próprio ou qualquer criatura mudar, e ainda assim ele não foi coagido a trair Cristo, mas propositadamente e com total liberdade 37

Schopenhauer sustenta que essa página não seria nada mais que uma paráfrase explicativa - apreciável exclusivamente por seu tom vivaz - da teoria kantiana do caráter inteligível. Ora, na Crítica da razão pura, Kant estabelece uma dupla causalidade operante nos atos de escolha humanos: uma causalidade natural e uma por liberdade. De uma parte, "todas as ações do homem no fenômeno se determinam, segundo a ordem da natureza, pelo seu carácter empírico e pelas outras causas concomitantes" 38 , de outra, tanto esse caráter quanto as causas cooperantes seriam a manifestação de um ato único de escolha originário e intemporal: precisamente, $\mathrm{o}$ caráter inteligível. Malgrado algumas oscilações 39 , essa teoria vem retomada também na "Elucidação crítica" que conclui o primeiro livro da Crítica da razão prática:

Nessa consideração [como coisa em si; VM], o ser racional pode agora dizer corretamente sobre cada ação contrária à lei praticada por ele, que poderia tê-la omitido, mesmo que ela esteja, enquanto fenômeno, suficientemente determinada no passado e seja nessa medida infalivelmente necessária; pois essa ação, com todo o passado que a determina, pertence a um único fenômeno de seu caráter, que ele [o ser racional; VM] fornece a si mesmo e segundo o qual ele imputa a si mesmo, enquanto

\footnotetext{
37 SCHELLING, F.W.J. Philosophische Untersuchungen, op.cit., pp. 277-278.

38 KANT, I. Crítica da Razão Pura, A549 B577 [Nota FN: trad. de M. P. dos Santos e A. F. Morujão, Lisboa: Fundação Calouste Gulbenkian, 2001]

${ }^{39}$ Cf. a sismografia detalhada de LANDUCCI, S. Sull'etica di Kant, Milão: Guerini, 1994, pp. 251-266.
} 
uma causa independente de toda a sensibilidade, a causalidade desses fenômenos.40

Para reassumir a terminologia proposta por Schopenhauer no escrito sobre a Liberdade da Vontade, a liberdade não consiste no operar, mas acima de tudo no ser: como no mito platônico de Er, uma vez escolhida uma dentre as vidas tecidas pelas Moiras, a alma não pode mais modificar o próprio destino.

Em que sentido Schelling aprofunda o discurso de Kant? Ele faz emergir a teoria kantiana do caráter inteligível de uma teogonia de origem böhmiana, fundada sobre aquilo que Heidegger chama de Seynsfuge. A distinção entre fundamento e existência permite explicar a origem do mal e, assim, fundar ontologicamente a liberdade como vivente faculdade do bem e do mal. Todavia, a presença da teoria de Kant tem contornos vagos tanto na argumen- tação de Schelling quanto no comentário de Heidegger ${ }^{41}$. Isso impede que se volte contra essa teoria a objeção fundamental que não reside mais em conciliar a liberdade de Deus com aquela do homem (a célebre pergunta do Da ira de Lactâncio: "Si Deus, unde malum?"), mas em conciliar a pluralidade das escolhas humanas entre si: encontramo-nos frente a uma pluralidade de centros livres, cada um dos quais deveria fazerse mundo (ainda que, como sublinha Landucci, limitadamente às séries causais pertinentes às ações do sujeito $(42)$, uma espécie de monadologia sem harmonia préestabelecida. A resposta de Hegel a essa objeção consistirá precisamente na re-instituição de uma harmonia pré-estabelecida, a astúcia da razão, que tece a trama da história com os fios das paixões e dos interesses individuais: nesse sentido, a liberdade é sempre histórica e coletiva, o indivíduo que possui o grau de liberdade que é dado a seu próprio tempo, não pode ser livre - quando o é - senão

\footnotetext{
${ }^{40}$ KANT, I. Crítica da Razão Prática, A175 [Nota FN: trad. de M. Hulshof, Petrópolis - Bragança Paulista, Vozes, p. 131]

41 Assim Heidegger retraduz na sua terminologia a teoria do caráter inteligível: "este ponto profundíssimo da mais alta amplidão do saber a si próprio na decidibilidade [Entschiedenheit] da sua mais própria essência, este ponto alcançam apenas alguns poucos, e raramente. E se [alcançam], então apenas enquanto esse piscar de olhos [Augen-Blick] do mirada mais íntima na essência também é instante [Augenblick], estritíssima historicidade. Isto quer dizer: a decidibilidade não recolhe a essência própria num ponto vazio da mera contemplação ociosa do eu [Ichbegaffung, Nota FN], mas a decidibilidade da essência própria é apenas o que ela é como resolutidade [Nota FN: Entschlossenheit]. Com isso queremos dizer o estar dentro no aberto da verdade da história, a insistência, que, antes de toda contagem e inacessível a todo cálculo, leva a cabo o que há de levar a cabo." (HEIDEGGER, M. Schellings Abhandlung, op.cit., p. 187)

42 LANDUCCI, S. Sull'etica di Kant, Milão: Guerini, 1994, p. 254.
} 
dentro do processo histórico e da própria comunidade política. A resposta de Schopenhauer consistirá, inversamente, na negação de toda forma de harmonia: o caráter inteligível é sim "um ato de vontade extratemporal e indivisível", cujo caráter empírico não é outro que "seu fenômeno [Erscheinung] no espaço, tempo e causalidade (essas figuras do princípio de razão suficiente, da forma do fenômeno"43, mas esse ato, que é "manifestação imediata [unmittelbare Erscheinung] da vontade" 4 , não é escolha também das causas cooperantes, dos motivos ${ }^{45}$, e assim de um mundo (embora limitadamente às séries causais que concernem à ação do sujeito). Perdese, pois, ou a Liberdade ou o Sentido: não é claro como Schelling possa salvar a ambos.

\section{O erro de Espinosa}

Resta agora enfrentar a questão decisiva que consiste na tentativa de compreender de que maneira Schelling teria mostrado o erro fundamental da filosofia de Espinosa. Heidegger parece referir- se a uma passagem do tratado de Schelling que nesse sentido é inequívoca:

E aqui de uma vez por todas, portanto, nossa opinião determinada sobre o espinosismo! Esse sistema não é um fatalismo, porque ele deixa as coisas serem conceituadas em Deus; pois, como mostramos, o panteísmo não torna impossível pelo menos a verdade formal; Espinosa há de ser, portanto, fatalista em virtude de uma razão completamente diferente e independente dessa. $\mathrm{O}$ erro do seu sistema não está de modo algum no fato de que ele põe as coisas em Deus, mas no fato de que são coisas - no conceito abstrato dos seres criados sim, até mesmo substância infinita, que para ele também é uma coisa. Por isso seus argumentos contra a liberdade são completamente deterministas, e de maneira alguma pan-

\footnotetext{
43 SCHOPENHAUER, A. Die Welt als Wille und Vostellung, in Werke (W), vol. II, p. 341.

44 Ibidem, p, 388.

45 O caráter atinge, pelo conhecimento, os motivos, segundo Schopenhauer. Por essa razão a conduta de um homem (isto é, a manifestação do caráter) pode mudar com base no grau de conhecimento "sem que seja lícito inferir-lhe uma alteração do caráter": pois o conhecimento não pode exercitar alguma influência sobre a vontade "mas [apenas] segundo o modo com o qual a vontade se revela nas ações" (ibidem, pp. 347 e 350 ).
} 
teístas. Ele trata também da vontade como um fato, e demonstra, então, muito naturalmente, que ela haveria de ser determinada em qualquer caso da efetuação por um outro fato, o qual, por sua vez, é determinado por um outro e assim em diante infinitamente. Daí a falta de vida do seu sistema, a falta de sentimento interno] da forma, a carestia dos conceitos e expressões, a intragável austeridade das determinações que tão bem coaduna com a forma de consideração abstrata; por isso, e de maneira completamente consequente, a sua visão mecânica da natureza.46 juízo de Schelling, glosa-o simplesmente afirmando que o erro do espinosismo não é teológico mas ontológico, o ente é concebido como coisa, como presente (Das Vorhandene), já que ele não "não conhece o vivente e nem mesmo o espiritual como modos próprios e talvez mais originários do ser" 47 , Contudo, Espinosa não entra nunca realmente em jogo no texto de Heidegger; quando é citado o é de modo superficial e não sem uma ponta de desprezo (para dizer a verdade, jamais racista, como no Schmitt daqueles anos, ainda que seja difícil não perceber o orgulho alemão que perpassa seu texto ${ }^{48}$. Entretanto, pelo menos em um caso, a total ausência de qualquer discussão não pode não ser relevada. Heidegger cita este trecho de Schelling:
O erro de Espinosa consiste em uma generalizada reificação: de Deus, da natureza, da vontade. Heidegger se detém somente no

\begin{abstract}
A filosofia da natureza do nosso tempo estabeleceu pela primeira vez na ciência a diferença entre
\end{abstract}

\footnotetext{
46 SCHELLING, F.W.J. Philosophische Untersuchungen, op.cit., p. 241.

47 HEIDEGGER, M. Schellings Abhandlung, op.cit., p. 107.

48 Relato em seguida algumas passagens de Heidegger: "o único sistema completo, construído até o fim em seu nexo fundacional é a metafísica de Espinosa [...]. Já o título traz à tona o domínio da exigência científica matemática - ordine geometrico. Que essa metafísica, i.e., ciência do ser total, se designa por "Ética", isso traz à tona que o agir e o comportamento do ser humano tem um significado determinante para o tipo de procedimento no saber e de fundamentação científica. Esse sistema, porém, apenas se tornou possível com base numa singular unilateralidade, sobre a qual falaremos mais tarde; ademais, porque os conceitos metafísicos fundamentais da escolástica medieval foram simplesmente acoplados no sistema com uma rara ausência de crítica. Para se levar a cabo o próprio sistema tomou-se a mathesis universalis, a doutrina do método cartesiana, e o conceito metafísico propriamente fundamental advém em todos os seus detalhes de Giordano Bruno" (Ibidem, p. 40-41); "Para evitar aqui um equívoco, esteja enfatizado que a filosofia de Espinosa não pode ser igualada com a filosofia hebraica. Já apenas o fato conhecido de que Espinosa foi expulso da comunidade hebraica é significativo. Sua filosofia é essencialmente determinada pelo espírito da época, Bruno, Descartes e a escolástica medieval” (Ibidem, p. 80).
} 
a essência, enquanto ela existe, e a essência, enquanto ela é apenas fundamento de existência. Embora esse seja precisamente o ponto em que ela desvia da maneira a mais determinada do caminho de Espinosa, ainda assim se pôde na Alemanha até hoje ser afirmado que seus princípios metafísicos eram os mesmos que os de Espinosa; e apesar de que precisamente aquela diferenciação é o que simultaneamente conduz à diferenciação mais determinada entre natureza e Deus, isso no entanto não obstava a que se a acusasse de misturar Deus com a natureza. 49
Schelling se distancia no Kampfplatz filosófico: poderíamos dizer que Schelling identifica aqui a própria filosofia diferenciando-a daquela de Espinosa. Ora, mesmo reportando fielmente a referência a Espinosa, Heidegger ignora-o completamente em seus comentários. Desde esse ponto, o nome Espinosa desaparece do texto por cerca das cem páginas que seguem. Seríamos tentados a atribuir a essa ausência uma significado sintomático, de ver nela o aflorar de um problema para a reflexão heideggeriana, como fez Balibar em um belo ensaio dedicado a Heidegger e Espinosa 50 . Mas talvez seja suficiente procurar explicar o passo schellinguiano para tentar compreender se Espinosa, com respeito a este, possa constituir um simples erro.
Heidegger cita integralmente essa passagem. Trata-se de uma passagem fundamental na sua interpretação, já que Schelling nela exprime a Seynsfuge que está no centro de toda leitura heideggeriana. Nela, Espinosa desempenha um papel central, é a teoria da qual

\section{O problema do mal}

A passagem que citamos das Investigações sobre a Liberdade é a chave teórica que permite a Schelling resolver o problema do mal: sobre a Seynsfuge se constrói a teoria schellinguiana do mal como

\footnotetext{
${ }^{49}$ SCHELLING, F.W.J. Philosophische Untersuchungen, op.cit., p. 249.

${ }^{50}$ Balibar defende que o silêncio de Heidegger sobre Espinosa seja sintomático do "puissant finalisme qui, paradoxalement, ne cesse de hanter la pensée 'négative' de Heidegger" [Nota DSS: "potente finalismo que, paradoxalmente, não cessa de assombrar o pensamento 'negativo' de Heidegger" ] (BALIBAR, E. "Heidegger et Spinoza" in Spinoza au XX siècle, BLOCH, O. (sous la direction de), Paris: PUF, 1993, ps. 327-343: 343. Cf. também VAYSSE, J, -M. Totalité et finitude. Spinoza et Heidegger, Paris: Vrin, 2004.
} 
perversão da relação entre os dois princípios.

A pergunta fundamental nesse ponto diz respeito ao sentido daquela referência a Espinosa, tratase, isto é, de compreender em que sentido Espinosa negou a distinção entre fundamento e existência. Heidegger, sobre tal ponto, não nos ajuda de fato, simplesmente não explica a referência; se, entretanto, tivesse que traduzir na sua filosofia a acusação de Schelling, teria talvez dito que Espinosa nega a diferença ontológica. Schelling parece afirmar a ausência de fundamento em Espinosa, ou seja, daquele princípio tenebroso que, embora não sendo mais perceptível no mundo da forma e da ordem, é todavia pensável. Para Espinosa tudo é luz, mas luz privada de vida e de liberdade, porque é luz geométrica em que Deus, o mundo e até a vontade são petrificados, são tomados por simples coisas. Quando Schelling expõe a teoria espinosana do mal, parece-me que essa interpretação venha perfeitamente à luz:

\section{[...] a força que se mostra}

no mal [seria] de fato comparativamente mais imperfeita que aquela que se mostra no bem, mas considerada em si, ou fora da comparação, seria ela própria, todavia, uma perfeição que, portanto, como qualquer outra, precisa ser derivada de Deus. O que chamamos nisso de mal é apenas o menor grau da perfeição, o qual aparece como uma falta apenas para a nossa comparação, não sendo falta alguma na natureza. Não se deve negar que essa seria a verdadeira assunção de Espinosa. 51

A luz da necessidade geométrica ilumina, embora de modo diferente, os graus do ser tornando de fato impossível a liberdade.

Alguns anos depois, nas Lições de Munique, Schelling rejeitará em Espinosa precisamente esse limite, ou seja, o fato de que nele o ser existe sem sujeito, excluindo todo não ser, toda potência, toda liberdade: trata-se pois de um ser

\footnotetext{
51 SCHELLING, F.W.J. Philosophische Untersuchungen, op.cit., p. 246. Heidegger, ao comentar tal passagem, assente plenamente à interpretação schellinguiana de tal aspecto sobre a teoria espinosana: "Concede-se que o mal valha como o não-bom, como falta, como imperfeito; o que falta não está aí; não-estar-aí, não estar presente -— assim chamamos o não-ente. Daquilo que, segundo sua essência, é o que não é, não pode, contudo, ser dito que seja um ente. Assim, a efetividade do mal é apenas uma ilusão. Aquilo que sempre é efetivo só pode ser o positivo. E o que há pouco chamamos de mal, e já por nomeá-lo falseamo-lo em positivo, esse imperfeito é, na medida em que é, sempre apenas um grau em cada caso diferente do bem - assim ensina Espinosa" (M. Heidegger, Schellings Abhandlung, op. cit., p. 122).
} 
impotente que não tem em si o poder de ser diverso daquilo que é ${ }^{52}$. E, na Filosofia da Revelação (lição VII), fará dele o campeão da filosofia negativa a que contraporá sua filosofia como filosofia positiva:

se, no entanto, Espinosa usa aquela verdade geométrica como exemplo para elucidar como, segundo a sua opinião, as coisas singulares seguem da natureza de Deus, a saber, de uma maneira igualmente atemporal, eterna, então a sua explicação do mundo é bem anti-histórica, e, em oposição a ela, ao contrário, a doutrina cristã pela qual o mundo seria efeito de uma livre decisão, de um fato, haveria de ser chamada uma explicação histórica.53

Se, então, a filosofia de Schelling faz vacilar a lógica de Hegel já que mostra a impossibilidade do conceito de retraduzir-se sem resíduos no tempo, de permear de si a temporalidade e a história nela anulando de fato a eventualidade, ela reconhece o erro fundamental de Espinosa na ausência total de história, de um âmbito humano que de algum modo exceda a luz da necessidade geométrica. Mas se trata realmente de um erro? $\mathrm{Ou}$ existe no pensamento de Espinosa alguma coisa que perturba a posição da simples alternativa Schelling-Hegel?

\section{Coisas e pessoas}

Antes de passar às conclusões, alguns breves pontos sobre a leitura schellinguiana de Espinosa. Seríamos tentados a dizer que não é tanto Espinosa que reifica Deus, os modos e a vontade, quanto, principalmente, Schelling que reifica uma palavra de Espinosa (é certo, pode-se reificar também o termo res!) fixando o seu conteúdo (de modo abstrato) exteriormente à estratégia teórica na qual está inserida. É verdade que Espinosa associa o termo res tanto a Deus quanto aos modos (não à vontade, porque esta se trata de um ens rationis) e, contudo, não se pode esquecer o fato de que no escólio I da proposição 40 da segunda parte da Ética haja uma crítica aos transcendentais:

\footnotetext{
52 SCHELLING, F.W.J. Münchener Vorlesung, in SW, vol. 5, pp. 104-105.

53 SCHELLING, F.W.J. Philosophie der Offenbarung, in SW, vol. 6, pp. 138-139.
} 
(...) a Mente humana poderá imaginar distintamente em simultâneo tantos corpos quantas imagens possam ser formadas simultaneamente em seu próprio corpo. Ora, quando as imagens se confundirem completamente no corpo, também a Mente imaginará confusamente todos os corpos sem qualquer distinção e os compreenderá como que sob um único atributo, a saber, sob o atributo do Ser, da Coisa etc. Isso pode também ser deduzido de que as imagens nem sempre têm o mesmo vigor e de outras causas análogas a estas, que não é preciso explicar aqui; pois para o escopo ao qual visamos basta considerar apenas uma. Com efeito, todas se reduzem a que estes termos significam ideias confusas em sumo grau. 54

O termo res indica uma ideia confusa que deriva tanto da incapacidade do corpo de conservar os traços de um número indefinido de encontros com os corpos externos quanto de traços de contornos indefinidos, efeitos de encontros recém mantidos: trata-se pois de uma noção que perdeu ou nunca possuiu o seu objeto, como escreve Macherey, é uma "quase-noção", "uma maneira de falar que se serve de articulação no discurso sem deter uma significação racional nela mesma,"55. Não há sentido algum, assim, em fixar a atenção sobre ocorrências do termo res na escrita espinosana, perdendo a estratégia teórica que a comanda 5 , para dar apenas um exemplo, se tomarmos em consideração as duas primeiras proposições da segunda parte da Ética ("Cogitatio attributum Dei est, sive Deus est res cogitans"; "Extensio attributum Dei est, sive Deus est res extensa"), seria de todo ilusório pôr o acento sobre a reificação de Deus -extrapolando o fragmento "(...) Deus est res (...)" - sem apreender a estratégia que aí está operando: um trabalho de redefinição da linguagem cartesiana das três substâncias agora no sentido da teoria da substância única da qual pensamento e extensão são atributos.

\footnotetext{
${ }^{54}$ Eth, in G, Bd. II, pp. 120-121. [Nota DSS: tradução brasileira da Ética, doravante tr. br, Grupo de Estudos Espinosanos da USP, São Paulo: Edusp, 2015, p. 199]

55 MACHEREY, P. Introduction à l'Éthique de Spinoza II, Paris : PUF, 1997, p. 307.

56 Trata-se, para ser exato, de 893 ocorrências (M. Gueret - A. Robinet - Tombeur, Spinoza Ethica, Concordances, Index, Listes des fréquences, Tables comparatives, Louvain-la-Neuve, Cetedoc, 1977, pp. 289-298).
} 
Voltemos à leitura de Schelling. Que coisa ele entende por "coisa"? Uma unidade fechada e privada de relações com o externo? $\mathrm{A}=\mathrm{A}$ ? Nesse sentido, em Espinosa não existe "coisa" alguma. Deus é causa de si no mesmo sentido em que é causa imanente dos modos (a sua essência é, pois, potência produtiva), os modos são compostos instáveis cuja essência reside na complexidade das relações instituídas entre suas partes e com o ambiente externo (e Jonas compreendeu com agudeza a originalidade da teoria do organismo espinosana), a vontade, enfim, não passa de um puro ens rationis defronte às volições singulares (que são ao mesmo tempo intelecções) e, elas mesmas, longe de serem coisas, são o lugar de condensação de complexas tramas relacionais que não apenas não reificam o indivíduo, mas impedem que este seja pensado como tal em sentido estrito (como, ao contrário, o fazem tanto Schelling como Heidegger), abrindo-o a uma dinâmica transindividual 57. Talvez, então, a acusação schellinguiana de reificação deva ser compreendida no seio da ideologia jurídica (burguesa, certamente - como sublinha Althusser 58 - mas retomada do direito romano e em particular das Istitutiones de Gaio): res é aquilo que não é persona, aquilo que não é dotado de liberdade e, assim, de responsabilidade. Não é por acaso que a indicação do erro fundamental de Espinosa faça um conjunto, em Schelling, com uma teoria do indivíduo humano entendido como persona que é, enquanto tal, responsável pelas próprias ações, não porque seja livre no tempo (toda ação singular é de fato determinada por motivos e, então, necessária), mas porque pôde, antes que o tempo fosse, determinar a própria essência (tanto Kant quanto Schelling e Schopenhauer insistem sobre a responsabilidade que sente o homem por aquilo que é e por aquilo que faz como sintoma desse ato originário de escolha do próprio caráter inteligível). Talvez então a identificação do erro espinosano, por parte de Schelling, não aponte tanto a reificação do indivíduo quanto, principalmente, a impossibilidade de sua classificação em relação à tradição teológico-jurídica da identidade pessoal que vê sua primeira grande expressão moderna no ca-

\footnotetext{
57 Cf. MORFINO, V. Ontologia della relazione e materialismo della contingenza in "Oltrecorrente" , 6, 2002, pp. 129-144. Cfr. também MONTAG, W. Chi ha paura della moltitudine? in "Quaderni Materialistti” , 2, 2003, pp. 63-79. Inspiração de ambos BALIBAR, E. Spinoza, il transindividuale, tr. it. di MARTINO, L. Di, PINZOLO, L. Milão: Ghibli, 2002.

58 ALTHUSSER, L. Réponse a John Lewis, Paris: Maspero, 1972, p. 73.
} 
pítulo sobre Identidade e diferença dos Essay de Locke ${ }^{59}$. Nesse sentido, o problema é sim o determinismo, mas talvez, de modo ainda mais radical, a não imputabilidade jurídica de uma ação a uma multidão ${ }^{60}$, que coisa é, com efeito, o indivíduo na teoria de Espinosa se não a configuração determinada de uma multidão (de ideias e de corpos)?

\section{Além do bem e do mal}

Voltando à questão do mal como privação, é verdade que Espinosa parece autorizar uma tal leitura, especialmente nas cartas a Blyenberg 61 . Trata-se, porém, a meu modo de ver, da necessidade de colocar-se sobre o terreno linguístico do correspondente ${ }^{62}$. Pode-se reencontrar em seu pensamento uma teoria bem mais profunda do bem e do mal segundo a qual estes não corresponderiam a um grau maior ou menor de perfeição do ser, mas principalmente a um efeito imaginário do preconceito antropocêntrico: a necessidade natural se encontra, em realidade, além do bem e do mal e a ontologização desses conceitos não é outra coisa senão a consequência da potência da imaginação que põe o homem como centro e medida do ser 33 . Quando Espinosa, depois, na quarta parte da Ética, define positivamente o bem e o mal, pode fazê-lo apenas em termos plurais e relativos, ou seja, não como escolha intemporal e absoluta entre amor cristão e egoísmo (isto é, a alternativa proposta por Schelling), mas na dimensão conjuntural do encontro dos corpos: "as coisas que fazem

\footnotetext{
${ }^{59}$ Neste capítulo são perfeitamente compreensíveis os enjeux teológico-jurídicos do conceito de identidade pessoal: a possibilidade da consciência de redobrar-se sobre a linha tempo reconhecendo no passado aquele mesmo self que é agora presente garante a infalibilidade da justiça divina que pode perscrutar nos corações, embora não daquela terrena que pode ser enganada pela linguagem.

60 É célebre o passo hobbesiano em que a discriminação entre povo e multidão passa precisamente por esse ponto: "O povo é uno, tendo uma só vontade, e a ele pode atribuir-se uma ação; mas nada disso se pode dizer de uma multidão" (Hobbes, T. De cive, XII, 8, in M, vol. II, p. 291) [Nota DSS: tradução brasileira de Renato Janine Ribeiro, São Paulo: Martins Fontes, 2002, p.189]

${ }^{61}$ Esta passagem [de Espinosa] parece ser particularmente relevante na leitura de Schelling seguida por Heidegger: “[...] a privação não é o ato de privar, mas simples e mera carência, a qual não é em si nada outro que um ente de razão, ou seja, uma espécie de pensamento que formamos quando confrontamos as coisas entre si. Digamos, por exemplo, que o cego é privado da vista porque somos levados a imaginá-lo como vidente, por efeito do confronto que fazemos seja com os outros que vêem, seja com o seu estado precedente. E porquanto consideramos este homem deste modo, isto é, comparando a sua natureza com aquela dos outros ou com aquela que perdeu, por isso afirmamos que a visão pertence à sua natureza e que portanto dela ele foi privado. Mas, se se considera o decreto de Deus e a sua natureza, não podemos afirmar daquele homem, mais que a pedra, que tenha lhe sido retirada a vista." (Espinosa a Blyenberg, XXI, in G., Bd IV, p. 128; tr. it. DROETTO, A. (org.),Turim: Einaudi, 1938, pp 133-134)

62 É um dado de fato relevante que as 11 ocorrências do termo privatio na Ética não digam respeito nunca à questão do mal, mas exclusivamente à da falsidade (GUERET, M. e ROBINET, A. Spinoza Ethica. Concordances, Index, Listes des fréquences, Tables comparatives, p. 275).

${ }^{63}$ Eth I, app., pp. 81-82 [Nota DSS: trad. br., op. cit. pp. 109-121]
} 
com que se conserve a proporção de movimento e repouso que as partes do Corpo humano têm entre si são boas; e más, ao contrário, as que fazem com que as partes do Corpo humano tenham entre si outra proporção de movimento e repouso" 64,

Para Espinosa, o homem tem tanto direito a existir e a agir quanto o tem o leão e o gato: o direito equivale à sua potência. Mas ele não pode escolher para si sua essência (em uma atemporalidade que, ainda que não precedendo o tempo, deve ser mesmo assim um lugar outro com relação ao tempo), tanto quanto não pode escolher para si um corpo (são ou doente), uma mente (sã ou doente), um sexo, uma cor de pele, um ambiente, um clima, uma família, uma sociedade, uma língua, um período histórico. Mais: não existe na filosofia de Espinosa uma essência feita de tal modo que preceda a existência e, nesse sentido, talvez ganhe pleno significado o silêncio de Heidegger sobre a ausência da Seynsfuge. A essência se faz na complexidade das relações (dos corpos, das mentes, com o ambiente, com a família, com a língua, com o próprio tempo), sem que tais relações to- mem a coloração do Zeitgeist que reduz sua complexidade e anula a contingência. As paixões não são propriedade do indivíduo que são ativadas por motivos, mas verdadeiras e próprias forças que existem entre o indivíduo e a causa que o gerou, como aparece nas proposições 5 e 6 da quarta parte:

Proposição V: A força e o crescimento de uma paixão qualquer e sua perseverança no existir não são definidos pela potência pela qual nos esforçamos para perseverar no existir, mas pela potência da causa comparada à nossa. (...)

Proposição VI: A força de uma paixão ou afeto pode superar as demais ações ou a potência do homem de tal maneira que o afeto adere pertinazmente ao homem. 65

Como escreve Montag, "os encontros com outros corpos, necessário para a conservação da coisa singular, inclui simultaneamente interações regulares e 'fortuitas'” 66.

\footnotetext{
64 Eth IV, pr. 39, p. 239 [Nota DSS: trad. br., op. cit. p. 439]

65 Eth IV, pr. 5 e 6, p. 214. [Nota DSS: trad. br., op. cit., p. 389]

66 MONTAG, W. Bodies, masses, power. Spinoza and his contemporaries, London-New York, 1999, p. 34.

67 As ocorrências do termo occursus são extremamente raras sob a pena de Espinosa. Uma, entretanto, é demais
} 
O occursus 67 , o encontro, tornase então o conceito chave na determinação da força (vis) de uma paixão, encontro entre potências (causae externae potentia cum nostra comparata) cujas desproporções podem produzir a dominância pertinaz (pertinaciter) de uma paixão concernente ao comportamento complexivo de um homem sem que isso seja atribuído à imutabilidade de seu caráter (isto é, se não a uma escolha intemporal, pelo menos a uma constituição essencial). Mas não somente, o encontro pode inclusive mudar a identidade mesma de um homem, o seu caráter (na terminologia kantiana), precisamente porque a identidade não reside em uma escolha intemporal mas em uma determinada proporção de movimento e de repouso entre as partes. É o caso do célebre exemplo de Gôngora citado por Espinosa:

Pois não ouso negar que o Corpo humano, mantidas a circulação do sangue e outras coisas pelas quais se estima que o Corpo vive, contudo possa mudar para uma natureza de todo diversa da sua. De fato, nenhuma razão me obriga a sustentar que o Corpo não morre senão mudado em cadáver; e mais, a própria experiência parece persuadirme do contrário. Com efeito, às vezes ocorre a um homem padecer tais mudanças, que não é fácil dizer que continue $\mathrm{o}$ mesmo, como ouvi contar sobre um Poeta Espanhol que fora tomado pela doença e, embora se tenha curado, ficou porém tão esquecido de sua vida passada que não acreditava serem suas as Fábulas e Tragédias que escrevera, e certamente poderia ser tomado por um bebê adulto se também tivesse esquecido a língua vernácula. 68

Nesse contexto teórico, a liberdade toma duas faces: 1) a liberdade como idêntica ao grau de potência e como contrário de coação, 2) a liberdade como causalidade adequada da ação. A primeira

\footnotetext{
significativa, no escólio da prop. 29 da segunda parte da Ética, quando são conectados conhecimento confuso e percepção da coisas "ex communi naturae ordine, hoc est (...) ex rerum (...) fortuito occursu" (G, Bd.II, p. 144). A importância do tema do occursus em Espinosa foi sublinhado por DELEUZE, G. Spinoza. Philosophie pratique, Paris: Editions de Munuit, 1981, passim; cf. também MARCUCCI, M. Occursus, 'Cosmologia negativa' e terzo genere, in DEL LUCCHESE, F., MORFINO, V. (a cura di), Sulla scienza intuitiva in Spinoza. Ontologia, politica, estetica, Milano: Ghibli, 2003, pp. 137-153.

${ }^{68}$ Eth IV, prop. 39, schol., p. 240. [Nota DSS: trad. br., op. cit. p. 441]
} 
diz respeito a todos os seres naturais: quanto mais estes são potentes, mais são livres. A segunda é a liberdade da razão enquanto conhecimento que nos permite agir - sempre de forma parcial e conflitiva, porém, de outro modo, uma parte da natureza se faria o todo na complexidadde de relações que nos constitui. A segunda concepção, que para os corpos políticos se identifica com um processo de democratização, está todavia implicada na primeira enquanto a razão não é outro da natureza, mas um grau de potência seu.

O erro de Espinosa consiste, pois, não tanto na reificação da vontade, quanto na refutação mais precisa de toda forma de antropocentrismo que procure atribuir a ela um império no império da natureza. E se esse erro fosse precisamente o ponto cego do idealismo, e não tanto a negação da história (seja entendida como marcha da ideia ou como advento do Cristo), mas precisamente a desconstrução ante litteram da dupla natureza-história? Nesse sentido, abre-se talvez uma ulterior via de interpretação, qual seja, ler o espinosismo não tanto como filosofia da luz em que a necessidade geométrica petrifica a vida, como Medusa sob seu olhar, mas como filosofia de um princípio tenebroso jamais sobrepujado pela luz, em que a luz (ou seja, a ordem e a forma) e o espírito (ou seja, a razão humana) não são senão efeitos aleatórios - em nada desejados, porque a treva não é desejo mas potência - do complexo jogo das trevas.

\section{Referências}

ALTHUSSER, L. Réponse a John Lewis, Paris: Maspero, 1972.

DELEUZE, G. Spinoza. Philosophie pratique, Paris: Editions de Munuit, 1981.

ESPINOSA, B. Ética, Grupo de Estudos Espinosanos da USP, São Paulo: Edusp, 2015.

HEGEL, G.W.F. Phänomenologie des Geistes in GW, BONSIEPEN, V. W. e HEEDE, R. (orgs.), Hamburgo: Meiner, 1980.

HEGEL, G.W.F. Wissenschaft der Logik in GW, Bd. 11, HOGEMANN, Von F., JAESCKE,W. (orgs),Hamburgo: Meiner, 1980.

HEIDEGGER, M. Schellings Abhandlung über das Wesen der menschlichen Freiheit (1809), FEICK, H. (org.), Tübingen: Max Niemeyer Verlag, 
1971 ; tr. it. MAZZARELLA, E. e TATASCIORE, C. (orgs.), Nápoles: Guida, 1998, p. 41.

JACOBI, F.H. Über die Lehre des Spinoza, HAMMACHER et alii, Hamburgo: Meiner, 2000.

KANT, I. Kants Werke (KW), Berlim: Walter de Gruyer \& Co., 1969.

LANDUCCI, S. Sull'etica di Kant, Milão: Guerini, 1994.

MACHEREY, P. Introduction à l'Éthique de Spinoza II, Paris : PUF, 1997.

MARCUCCI, M. Occursus, 'Cosmologia negativa' e terzo genere in DEL LUCCHESE, F. e MORFINO, V. (orgs.), Sulla scienza intuitiva in Spinoza. Ontologia, politica, estetica, Milano: Ghibli, 2003.

MONTAG, W. Bodies, masses, power. Spinoza and his contemporaries, London-New York, 1999.

MORFINO, V. Ontologia della relazione e materialismo della contingenza in "Oltrecorrente" , 6, 2002.

SCHELLING, F.W.J. Sämtliche Werke (SW), SCHRÖTER, M. (org.), Munique: Beck'sche Verlagsbuchandung, 1959.

SCHOPENHAUER, A. Sämtliche Werke (W), HÜBSCHER, A. (org), Wiedsbaden: Brockhaus, 1972.

SPINOZA, B. Ethica in Opera (G). GEBHARDT, G. (org.), Heidelberg: Carl Winters, 1972.

Recebido: 04/07/2019

Aprovado: 09/11/2019

Publicado: 17/11/2019 
